\title{
ECONOMÍAS-OTRAS: INTRODUCCIÓN A UN MONOGRÁFICO NECESARIO
}

\author{
ECONOMIES-OTHERS: \\ INTRODUCTION TO A MONOGRAPH REQUIRED \\ Ángel Calle Collado \\ Universidad de Córdoba \\ angel.calle@uco.es \\ Isabel Álvarez Vispo \\ Red URGENCI (Red Intern. De Agricultura Sostenida) \\ ekofemineska@mail.com
}

\section{RESUMEN}

Este trabajo realiza una crítica de la noción convencional de economía, para situarla en la satisfacción de necesidades en un marco de límites ambientales. Desde ahí construimos un marco de referencia para las Economías-otras, entendiendo por tales aquellas que beben de perspectivas de la Economía de cuidados, la Economía social-solidaria y la Economía ecológica. A partir de ellas, se re-introducen alternativas a la idea de "desarrollo" sobre la base de miradas que han cobrado actualidad (decrecimiento con justicia, feminismo, sustentabilidad fuerte) y prácticas que surgen alrededor de (nuevas) formas de cooperación social (Nuevos comunes)

\begin{abstract}
This work criticizes the conventional notion of economics, to place it in the satisfaction of needs within a framework of environmental limits. From there we build a frame of reference for other Economies, understanding those that drink from the perspectives of the Care Economy, the Social-Solidarity Economy and the Ecological Economy. From them, alternatives to the idea of "development" are re-introduced on the basis of looks that have become current (decrease with justice, feminism, strong sustainability) and practices that arise around (new) forms of social cooperation (New commons).
\end{abstract}

\section{PALABRAS CLAVE}

Economía crítica, decrecimiento, cuidados, economía social-solidaria, Nuevos comunes

Códigos JEL: J00, J20, J22.

Fecha de recepción: 04/10/2019

\section{KEY WORDS}

Critical economics, decrement, care, social-solidarity economy, New commons.

Fecha de aceptación: 11/11/2019 



\section{LA ECONOMÍA TIENE QUE VER CON LA VIDA}

La aproximación al análisis de lo económico en clave de necesidades e interdependencias sociales y ambientales está lejos de constituir lo que usualmente entendemos por "economía". Siguiendo a Karl Polanyi (2009), podemos decir que, bajo un capitalismo crecientemente financiarizado, los modos de integración de la economia (la manera en que ésta induce una sociedad) no caminan hacia el sostenimiento de la vida, antes al contrario. Convencionalmente la economía aparece ligada a parámetros que nos hablan de niveles de consumo, agregaciones monetarias que dan lugar al llamado "producto interior bruto" y de circulación de materias, servicios y apuestas especulativas en torno a "mercados globales". La "riqueza" queda incrustada en lo útil, escaso y que hace circular productos y personas, con el único y parco objetivo de producir "la continua expansión del carrusel de la producción y del consumo" a través de una hiperinflación de deseos sobre lo escaso y mercantilizable (Naredo 2003: 123). Bajo la ciencia y los sistemas económicos puestos en pie, y a pesar de las numerosas corrientes críticas como las que aquí se abordan, la vida lleva décadas sin estar presente como enfoque, como medio o como fin en lo que nos comunican las páginas salmón de los periódicos o en las declaraciones en torno a lo "económico" de los líderes políticos que se reúnen en el G7.

La economía hegemónica es hoy capitalista, patriarcal y mundializada, un sistema-mundo económico que no político como señala Wallerstein (1997), o al menos no inspirado por una democratización para compartir decisiones y sostener necesidades a cubrir de manera global (mundial e integral). Las nuevas corporaciones empresariales cuentan, en términos económicos y de capacidad de presión política, con mayor poder real que los Estados-nación. Las 10 multinacionales más grandes tendrán un valor que superará el PIB conjunto de 180 países, entre los cuales estarían la India o Irlanda. El presupuesto del Estado español es inferior a la cifra de negocio de Wall-Mart. Los Estados son más "flacos" a partir de la desregulación de determinadas fronteras económicas iniciada en los 80. Lo cual no ha sido óbice para aumentar el poder de estos Estados en temas de seguridad (interior, exterior) y en capacidad para apoyar lógicas neoliberales mediante el fortalecimiento de Bancos centrales autónomos, la Organización Mundial de Comercio o la puesta en pie tribunales internacionales mercantiles que 
pueden hacer que una multinacional siente en el banquillo de los acusados a un Estado por no atender los fundamentos de una economía neoliberal. Estas multinacionales (El top 5 de capitalización bursátil: Aple, Google, Microsoft, Facebook y Amazon) constituyen motores de éxito para nuevos modelos políticos (piénsese en el ascenso de Trumpo Bolsonaro) y de fracaso de modelos productivos más ligados a la economía real (desaparecen las tiendas locales que priorizaban compras de producción local). La economía aumenta "la riqueza", medida en sus indicadores, aunque no la felicidad ni el bienestar de la gente.

Pero hay otras economías sin las cuales no podrían concebirse y sostenerse estas economías especulativas. Son economías sociales, más esenciales en la medida que cualquier edificio económico las necesita. ${ }^{1}$

Gráfico 1. La relación (reales y mediatizadas) de las diferentes economías contexto de "globalización"

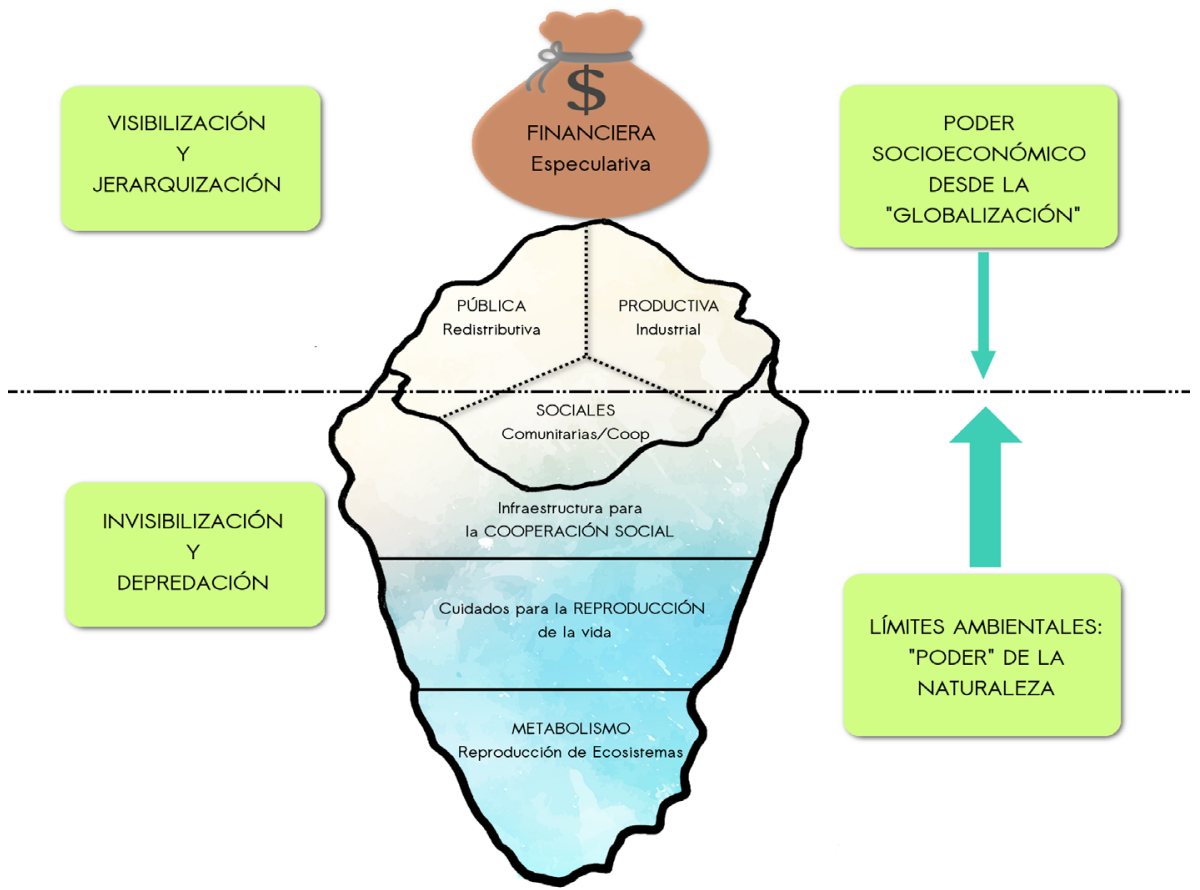

Fuente: tomado de Calle, Piñeiro y Suriñach (2017)

1 El gráfico trata recoge perspectivas ecofeministas y de economía ecológica, ya referenciadas, y que podemos seguir en los trabajos de C. Carrasco, A. Puleo y O. Carpintero. 
Las economías "invisibilizadas" nos organizan el metabolismo y la satisfacción de necesidades, así como la posibilidad de que la vida continúe en medio de torbellinos que apuntalan el vuelco climático, la insostenibilidad derivada del crecimiento exponencial de uso intensivo de materiales y energías fósiles, las desigualdades y las hambrunas del planeta. Esta punta del gran iceberg económico, a nuestro pesar, representa hoy la foto que reemplaza en los imaginarios colectivos al conjunto de economías que atienden nuestras necesidades.

El capitalismo de base especulativa, en alianza con otras dinámicas de exclusión y depredación, reemplaza las otras economías tanto en un plano simbólico como material. La economía hegemónica nos va quitando condiciones con que vivir a la vez que se ofrece como la única respuesta para encontrar mejores posibilidades de "vida"

\section{2. ¿POR QUÉ DECIMOS QUE LA ECONOMÍA ACTUAL} NOS QUITA CONDICIONES DE VIDA?

El capitalismo desarrolla extralimitaciones que se traducen en la imposibilidad de seguir manteniendo crecimientos aritméticos - exponenciales de su producto interior bruto. Nos referimos fundamentalmente aquí a límites sociales y ambientales. La situación se agrava a nivel mundial. Un $1 \%$ de las élites planetarias controla la misma riqueza que el $99 \%$ restante.

Desde la crisis de 2008 este descontento se expresa incluso en los países centrales europeos, con un paulatino descenso de las expectativas económicas, sobre todo de los sectores más jóvenes, siendo reflejo de la caída de indicadores sociales. Junto a las consecuencias sociales de la injusticia (hambrunas, migraciones, explotación laboral) sabemos también de descontentos que se transforman en grandes oleadas de protestas, donde lo político y lo ambiental comienza a entrelazarse. Son las "revueltas del pan" que han seguido a los planes de ajuste estructural, que derivaba en subida de la cesta básica de alimentos o en energía, del Banco Mundial (en países del llamado Sur) o de gobiernos neoliberales (en países centrales) desde la década de los 80 del siglo pasado. Se han manifestado recientemente en protestas o insurrecciones políticas que van de la "primavera árabe" a las manifestaciones mundiales reconocidas con el lema "Occupy Wall Street" en la década de 2010. Son hoy los chalecos amarillos en Francia, las manifestaciones del mundo rural en España, las convocatorias del movimiento estudiantil frente al cambio climático, las luchas territoriales y ambientalistas de América Latina frente a los expolios protagonizados por compañías interesadas en recursos energéticos, 
minerales o en el control de la biodiversidad, así como las protestas frente las quemas que buscan hacer avanzar el monocultivo ganadero y sojero en países como Brasil. El ataque general a la vida ha tenido, como revulsivo y como colofón, el despegue de un muy diverso movimiento feminista que ha construido hitos y redes de protesta internacionales en el último lustro visibilizándose con fuerza en las huelgas y manifestaciones del $8 \mathrm{M} \mathrm{El} \mathrm{auge}$ de movimientos nacionalistas o de la extrema derecha tiene que ver en gran parte con esa desafección política y los miedos a una "globalización" a la que no se ve "globalizar" la justicia, las decisiones o las oportunidades para quienes están más abajo. Al no funcionar los resortes institucionales como parlamentos, gobiernos o tratados, o funcionar en sentido contrario, el descontento se canaliza hacia una nueva política, de distinto signo ideológico, la cual, a su vez, alberga programas económicos donde aparecen enfrentadas las propuestas neoliberales (ultraconservadoras) y las partidarias de un decrecimiento con justicia.

Junto a estos límites "externos", a los que cabría añadir la propia disponibilidad de petróleo y minerales accesibles y baratos en mercados internacionales, el capitalismo enfrenta límites "internos". Por un lado, la economía productiva e industrial (la economía "real") ha sido devorada por un capitalismo meramente especulativo: puede generarse más "riqueza" a costa de destruir las bases productivas, las economías comunitarias - la propia naturaleza (Etxezarreta 2015, Aguilera 2013, Riechmann 2012). Paralelamente, y como consecuencia de lo anterior junto con el agotamiento de un consumo de las capas más bajas, el capitalismo no encuentra márgenes rápidos de ganancia en el tejido productivo de antaño (Husson 2013). En España, por ejemplo, cerca de medio millón de empleos han sido destruidos en sectores industriales o de telecomunicaciones (considerados más productivos) entre entre 2010 y 2017. Los grandes fondos de inversión aterrizan en el sector alimentario, ocasionando crisis como la acontecida a escala mundial entre 2007 2008, ocasionando escasez de trigo o arroz a pesar de las altas cosechas. Se impulsa la creación de mercados mundiales de sectores primarios (agricultura, minería) o de baja inversión y fuerte retorno inmediato como el turismo internacional. Pero aún así no consigue despegar: . Están afectando crisis políticas como el Brexit, la guerra comercial entre China y Estados Unidos o las luchas por el control territorial del menguante petróleo en el mundo. Pero no es menos cierto que algo va mal en el propio seno capitalista. No vamos a volver, y nos referimos a los países centrales, a los felices años 70 y la década de endeudamiento del Sur (desde los 80 para acá, en los países mediterráneos más recientemente) que aportaban savia financiera y lucros a los centros industriales (Alemania como locomotora industrial de Europa, Estados Unidos como país endeudado tirando del consumo mundial). 
Y lo que se agrava por arriba, se manifiesta por abajo en conflictos sociales y también de naturaleza interna para los propios individuos. Las desigualdades por razones de género se hacen más evidentes. La crisis ha supuesto más presión en los hogares a partir de 2008 y en particular más reclamación de esfuerzos sobre las mujeres: "las mujeres registran tasas más elevadas en AROPE [indicador de pobreza y exclusión], riesgo de pobreza, privación material severa, baja intensidad de empleo en el hogar, pobreza severa y todas las variables relativas al mercado de trabajo"2. Los ajustes neoliberales, la reducción de servicios públicos y, en primer lugar, las dinámicas patriarcales de división sexual del trabajo en el interior de los hogares trasladan la crisis económica financiera hacia el corazón de las economías del cuidado, aumentando la presión sobre familias pobres y en particular sobre mujeres (Gálvez y Torres 2010). Desigualdades que trasladan a buena parte de la población (en países centrales ahora es más evidente) hacia economías productivas más precarizadas. Se abre la puerta de entrada hacia dinámicas estructurales de exclusión, pobreza, pérdida de vivienda estable o situación de desempleo crónica. "Estoy en cólera porque trabajo para nada", comenta un joven chaleco amarillo. "Se compran amigos y abrazos: la epidemia de soledad en EE UU ya es un negocio" reza un titular de El País ${ }^{3}$. La esperanza, parece ser, es lo último que se mercantiliza.

Nos estamos enfrentando, a escala micro y macro, a Los límites del crecimiento según el informe del Club de Roma, publicado en 1972. Las otras economías que tienen que ver con la vida (los ciclos del agua, el plato que se pone en las mesas, o las mediaciones vecinales) están hoy más sometidas, más apartadas, aunque se reconozca progresivamente su importancia social, para nuestra especie. Extralimitaciones sociales y ambientales que a escala planetaria, estallan como conflictos, que hoy tienen apariencia de guerras comerciales o petroleras. América Latina y África son hoy escenario de una disputa comercial entre Estados Unidos, China o la Unión Europea por minerales cada vez más escasos (hierro, cobre, los llamados minerales "raros") o por la propia disponibilidad de tierras para el comercio internacional de alimentos. No desaparecerán de la faz de la Tierra, si no que serán elementos de difícil acceso y probablemente sólo disponibles para determinadas élites o sectores considerados estratégicos (telecomunicaciones, aparato militar, infraestructuras energéticas).

Nada extraño, ni nada nuevo, sólo que intensificado y aproximándose a los límites bajo el impulso de la llamada "globalización". La depredación es una práctica sistemática inherente históricamente a las economías

2 Ver https://www.eapn.es/estadodepobreza/ARCHIVO/documentos/Informe_AROPE_2018.pdf, pg. 5

3 Ver https://elpais.com/sociedad/2019/07/29/actualidad/1564417043_013460.html 
capitalistas (Harvey 2019). La invisibilización de cuidados (Federicci 2004, Ezquerra 2011), y de las funciones ambientales desde diferentes comunidades y territorios o la contribución de personas empobrecidas a la construcción de una fábrica social mundial, constituyen una normalidad de sistemas que necesitan crear enclaustramientos económicos y políticos para poder avanzar (Calle 2015).

\section{3. ¿POR QUÉ MIRAR HACIA OTRAS ECONOMÍAS?}

Nuestras sociedades se enfrentan hoy a tres grandes retos que tienen que ver con la recuperación de economías reales que atiendan la realidad del vuelco climático y sean conscientes de nuestra vulnerabilidad como seres humanos:

1. el sostenimiento real de cuerpos, desde una perspectiva de bienestar físico y emocional y que precisa forzosamente de una sociedad que albergue sentidos colectivos e igualitarios (identidad, economías, culturas) y proteja la fertilidad de la tierra y de sus huéspedes (solidaridad intergeneracional, inter-especies, entre seres humanos)

2. el desmembramiento de lazos sociales que son instrumentos de mediación, de sentido, de capacidad para repensar otras economías; nos ahogamos física y mentalmente en una sociedad más líquida, más cínica, más inmediatista y que se pierde (piscológicamente) a través de la nueva tecnologías de información y comunicación;

3. la posibilidad misma de seguir construyendo experiencias humanas cuando la casa planetaria se cae encima de la humanidad, pensando en clave de transiciones posibles.

Es ya percibible el colapso socioambiental en el cuarto mundo de los países ricos, en los países y comunidades donde la extracción de recursos se envuelve en violencia, en las zonas que progresivamente se abandonan por guerras o falta de expectativas vitales. Va más allá de la implosión de sociedades, de la insostenibilidad de cómo manejamos el planeta. Son los mismos cimientos civilizatorios, inclusive para las economías centrales del planeta, los que se tambalean. Se trata de toda una ruptura civilizatoria (Calle 2013) que, puntualmente, va respirando contestaciones, en muy diversas direcciones como la primavera árabe, en Francia los llamados "chalecos verdes" que son respuestas (quizás aún balbuceantes) a quién va a pagar el cheque de la forzosa transición energética o los $8 \mathrm{M}$ cada vez más masivos en todo el mundo en respuesta a la violencia machista física y estructural.

La realidad podría ser otra, hay otros modos de integración, otra economías nos diría Polanyi. La circulación socio-económica pone en juego bienes, mercancías o contratos entre los seres humanos. Y éstos pueden hacer funcionar esta circulación desde una solidaridad (economías del 
don libre) hasta formas de explotación o expoliación (unas personas son obligadas a dar a otras). Entre medias, quedarían formas más "pactadas", como pueden ser: los intercambios que se dan en mercados (mercantiles, de trueque) o por la costumbre (rituales); las reciprocidades que se asocian a favores o formas de apoyo mutuo; o también las derivadas de obligaciones adquiridas (prestaciones de servicios, contratos). En cuanto a la redistribución, puede refugiarse en planos microsociales como un hogar o unidad doméstica; puede generar dinámicas macrosociales de re-equilibrio en clave de derechos (Estado) o solidaridades y formas de caridad de carácter privado (redes de apoyo, ONGs, iglesias); o puede no acontecer entre grupos distantes porque nos movemos en fórmulas de autogestión, autoabastecimiento o economías comunitarias. En un plano contrario, la redistribución puede ocurrir de abajo hacia arriba, un revolución de las élites, a través de instituciones que imponen circulaciones o expoliaciones como empresas que se benefician de políticas neoliberales, puertas giratorias, corruptelas, exención de impuestos, burbujas poco transparentes en paraísos fiscales, etc.

Diversas personas expertas en economía crítica (Etxezarreta 2015, Toussaint 2018), coinciden en señalar que el vórtice capitalista no ha variado mucho en las últimas décadas bajo la llamada "globalización". Ha continuado con su extralimitación en dos planos: la creciente financiarización (con la consiguiente invisibilización de lo no monetarizado)y el agotamiento de recursos y energías fósiles. Ha acabado imponiendo una razón autoritaria, neoliberal y depredadora. Ha desplazado hacia modelos y organizaciones tecnocráticas donde el mercado mundializado es todo a lo que debe aspirar la política: lo público y cómo se representa o gestiona. Y donde lo político (ética, percepciones y lazos sociales que se dan en lo cotidiano) queda restringido a las estrategias de supervivencia (sea el emprendedurismo o actividades consideradas ilegales) y a la integración presuntamente cosmopolita en un consumismo cool (Lenore 2014).

¿Por qué entonces debemos mirar hacia otras economías si se trata de una razón "triunfante"? En primer lugar, porque los peores escenarios imaginados por gran parte de la crítica económica se están haciendo realidad, en el planeta, en la política y en nuestros cuerpos. Decía Norberto Bobbio, que, bajo la economía capitalista, la democracia liberal había cometido un gran pecado: haberse quedado a las puertas de las fábricas. La política se convirtió en muchos casos en un condimento o un apéndice de las agendas que imponen megaproyectos industriales o extractivos (Aguilera 2016); o de regímenes financieros que se benefician de un poder omnímodo del crédito y los mercados de deuda (la llamada deudocracia, Toussaint 2018). Hoy, al contemplar el oleaje conservador que se aproxima paulatinamente (en voces, formas y propuestas) a un fascismo de nuevos 
ropajes, vemos que lo que algunos llaman una "democracia iliberal" (Mounk 2018) es en realidad un desafío totalitario que sopla muy a favor del neoliberalismo (Calle 2018).

En segundo lugar, porque como afirma Naredo la economía convencional se ha desentendido de todas sus bases materiales. El motor del crecimiento monetario ha sido un dispendio de energía barata (Fernández y Reyes 2014), una gran fiesta para las personas (especialmente hombres) afortunadas de vivir y nacer en los países centrales y bajo los "30 gloriosos años del capitalismo" (1945-1975). Este deambular de la economía por encima de lo terrenal y al amparo del lo especulativo provocará serios "trompazos" en nuestras vidas (Herrero y Reyes 2011, Riechmann 2008). La economía real-real (de la naturaleza) pondrá en su sitio a la economía productiva (economía que vemos como "real" ahora) e informará a la economía inexistente (consumidora-especulativa) que el dinero no se puede comer.

Y no parece que haya margen para un New Green Deal basado exclusivamente en políticas públicas que apoyen una "reindustrialización verde". Es decir, recrear un "nuevo contrato" industrial-social "reverdecido" que permita conjugar crecimiento del PIB y del consumo con economías progresivamente descarbonizadas, "sostenibles" incluso ${ }^{4}$. En general los enfoques de crecimiento descarbonizado (muy bajo en emisiones de gases que producen el "efecto invernadero) basan las bondades del "nuevo contrato reverdecido" en:

- la creencia que la apuesta por energías sostenibles nos permitirá mantener las demandas energéticas actuales;

- la confianza en el desarrollo de tecnologías y aparatos que, en su uso, sean mucho más eficientes en su consumo y demandas de materiales y mucho menos contaminantes;

- la apuesta por un Estado como vehiculo que es posible desviar hacia la conducción de transiciones solidarias y sustentables en el actual marco económico y político

- la comprobación de que la apuesta por una descarbonización de la economía se ha iniciado en países centrales;

- el crecimiento demográfico se parará y la humanidad se estabilizará en torno a los 10.000 o 12.000 millones y, mediante una nueva cultura de consumo y de alimentación, podremos reducir la huella ecológica, la implosión metabólica asociada a una dieta cárnica, etc.

4 Para una panorámica general, ver la introducción que realiza Luis González Reyes al libro "Decrecimiento vs. New Green Deal" (editado por Traficantes de Sueños, 2019), que recoge una colección de artículos y visiones con respecto al posible contrato verde como hipotética alternativa a un decrecimiento forzoso y radical. Ver también el trabajo por una apuesta de conquista de derechos sociales y ambientales desde las políticas públicas el texto de Santiago Muiño y Tejero (2019) 
- Un intento de resignificar a la ciudadanía como consumidora y no como sujeto político y de derecho., omitiendo cómo la protesta y las alternativas sociales han sido clave en la búsqueda de la justicia social.

Se trataría de un keynesianismo verde, un empuje estatal que podría adentrarnos en un capitalismo estacionario o postcrecentista, en lo que se refiere a movilización de energías o de valores monetarios (verJackson 2017). Existen "grandes peros" a las hipótesis y afirmaciones que manejan estos sectores que tratan de eludir apuestas de decrecimiento (metabólico) con justicia (social y planetaria), como argumentan diferentes autores (VV. AA. 2019, González Reyes 2019). En primer lugar el propio enfoque. Vuelve a situar el foco (lineal y seccionado lejos de un enfoque sistémico) en la parte superior del iceberg económico, el productivo-real y el meramente especulativo. Elude pronunciarse sobre el límite a la obtención de materiales y elude analizar la degradación de ciclos vitales, el progresivo deshielo de los casquetes polares o las bruscas alteraciones climáticas que puedan desprenderse de las anteriores alteraciones. Asimismo asume que la sociedad normalizará la precariedad y la subordinación a los modelos propuestos desde el modelo Estado-global.

Situándonos incluso dentro del propio modelo economicista de un capitalismo atemperado y reverdecido hay cuentas que no nos salen. Un "nuevo modelo productivo" requiere un transición en términos de aparatos, infraestructuras e incluso instituciones. Pero lo que nos queda de materiales que han sido esenciales para nuestra industria actual junto con un petróleo barato no se está invirtiendo en esta dirección: ¿de dónde saldrán los insumos que se están agotando? ¿Dónde están las baterías que doten de autonomía a grandes camiones (hoy limitada a menos de 500 kilómetros y con menos peso a cuestas)? ¿Tienen las energías alternativas capacidad para alimentar un "desacoplamiento"? Los pocos estudios que existen son demoledores: o cambiamos radicalmente o cambiamos radicalmente. Como afirma Prieto (2019): "Si la energía solar se tuviese que hacer cargo del reemplazo de la energía primaria que el mundo consume, para llegar a una descarbonización, no llegaría a cubrir ni el 1\% de la demanda".

Así mismo la producción "verde" puede ocasionar una mayor demanda energética y de materiales. Es el caso de la producción de coches eléctricos o de los nuevos smartphone ${ }^{5}$. También asumimos ya como

5 Para construir 2.000 millones de vehículos eléctricos y sustituir los de explosión se requeriría doblar la producción de cobre, multiplicar por 3,5 la de cobalto y por 1,7 la de materiales como neodimio y disprosio, lo que aceleraría nuestra extralimitación al disminuir aceleradamente los recursos y demandar la fabricación (y nuevas extracciones) de nuevos bienes tecnológicos; ver entrevista a González Reyes, co-autor junto con Ramón Fernández 
"descarbonizados" ciertos sectores como el de las telecomunicaciones. Pero están lejos de estar "en el aire": consumen más del $4 \%$ de toda la energía del planeta (Turiel 2018). O el "efecto rebote" que se ocasiona al saber que algo consume (aparentemente) menos energía: fotocopiamos más y seguramente utilicemos más la lavadora si creemos que está movida por menos energía y es energía "limpia". Se apela, con la misma cortedad de miras, al argumento de la reducción de emisiones de CO2 que han experimentado grandes economías como Alemania o Estados Unidos, consideradas como ejemplos de una "transición hacia una nueva economía climática"b. Lo que no se visibiliza es que las emisiones globales siguen aumentando en ese periodo: buena parte de la industria mundial se traslada a China y de la agricultura intensiva a África, con lo que parece que el Sur se está volviendo más contaminante, cuando esos productos son fruto de la demanda y el modelo productivo que imponen las economías centrales.

La respuesta en clave de decrecimiento con justicia tampoco tiene el camino allanado. La llamada "tesis colapsistas" vendría a decirnos que escenarios de decrecimiento forzoso concederán más legitimidad y afán de supervivencia a la construcción de otras economías. Cuanto peor resuelta la transición, ¿mejores transiciones? No parece el caso. Hoy el decrecimiento forzoso es un decrecimiento de mercado: a menos energía consumida ha habido más pobreza energética, ya que la variable justicia social no ha entrado en juego tras la crisis del 2008; si tenemos menos herramientas para iniciar una transición (planes de contingencia, nuevas infraestructuras, alternativas económicas) tendremos menos opciones de salir de un capitalismo crecientemente piramidal, feudalizado, ávido de encontrar alianzas en gobiernos autoritarios.

Es posible y absolutamente necesario, sin embargo, un Nuevo Contrato EcoSocial, un Social-New Green Deal para los amantes de los debates anglosajonizados. Pero donde lo Social entra con mayúsculas y es la base del cambio. Los adalides de un New Green Deal, ahora recogido por líderes políticos en diversas partes del mundo cercanos a un intento de renovación "verde" de la socialdemocracia de antaño (Ocasio-Cortez, Jeremy Corbin, Carmena y Errejón en este país), postulan cambios situando el Estado y las políticas públicas como la razón y la fuerza centrales. Se habla también de estrategias duales: sociedad civil y políticas públicas (Santiago Muiño 2019).

Durán del libro En la espiral de la energía, en la plataforma digital Rebelion (18-06-2015) [http://www.rebelion.org/noticia.php?id=200111]

6 Ver el trabajo de N. Aden "The Roads to Decoupling: 21 Countries Are Reducing Carbon Emissions While Growing GDP", proyecto de estudio y blog financiado por World Resources Institute https://www.wri.org/blog/2016/04/roads-decoupling-21-countries-are-reducingcarbon-emissions-while-growing-gdp 
Pero en buena medida considerando al Estado como gran ingeniero social que abre las puertas y no como simpatizante histórico de la causa neoliberal.

La historia, la economía institucional y la conformación de esas (sostenibles) costumbres en común apuntan a lo contrario, siguiendo a E.P. Thompson o E. Ostrom Si existen derechos socioeconómicos en algún rincón del mundo es porque el músculo social y sus principios han sido laboratorios y herramientas de presión precedentes. Las políticas "agroecológicas" en Brasil han terminado siendo políticas para sostener industrias certificadas eco, grandes productores, comercio exterior hacia los consumidores reverdecidos de los países del Norte. Mínimamente se han favorecido mercados más locales, derecho a la alimentación o el aumento de la biodiversidad cultivada. Las políticas "de transición energética" en Alemania no han buscado otros modelos productivos y energéticos, se quiere seguir haciendo lo mismo pero de forma "reverdecida", con lo cual el efecto rebote y el aumento de la presión sobre recursos mundiales están servidos, y de ahí vendrán nuevos e insostenibles crecimientos de la huella ecológica global en el mundo. Se habla de un New Green Deal apostando por insistir en la (des)planificación inmobiliaria y no por desarrollar otras ciudades y crear nuevos derechos. La búsqueda de votos de la socialdemocracia reverdecida no parece caminar en pos de unas políticas de transición ecosocial con justicia.

Por todo ello, las Economías-otras precisan experiencias y articulaciones reales que planteen alternativas. Han de buscar mayorías sociales que asuman en su vivencia y doten de legitimidad a otras formas de hacer la economía (Prats 2019). Los Estados no van a crear esas condiciones, se han manifestado más favorables a los tratados neoliberales y las inversiones en más infraestructuras que a los acuerdos reales de lucha frente al cambio climático. A través de políticas del "procomún" están sentando bases de experiencias que denominamos Nuevos comunes": procesos sociales que apuestan por una mayor autogestión y cogestión público-comunitaria tanto de bienes naturales (mediante manejo sostenible de ecosistemas, aumento de la biodiversidad cultivada, energías alternativas, cuidado de ciclos del agua, etc.) como de bienes cooperativos (desde mercados hasta formas de producir, distribuir y espacios para compartir anclados en un territorio y en la cooperación social). Aquí se dan cita los viejos comunales que sostenían montes o bancos de pesca, como los nuevos comunes globales referidos a la creación compartida de conocimiento, monedas sociales o mercados que refuerzan lazos sociales y con el territorio. Sin cultivar una sociedad de bases cooperativas, solidarias y sustentables no habrá decrecimiento con 
justicia: o no hay decrecimiento o no hay justicia y, seguramente en el futuro inmediato, ni uno ni otro.

La disputa por otras economías es cuestión de realidades, ya emergentes, pero también de abordary reconstruir la genealogía de nuestras economías, cada quien en su contexto político, cultural y ecosistémico. Para ello es necesario no sólo otros prismas, también mirar desde otros territorios y culturas, como hemos tratado de hacer en este monográfico.

\section{EL RING DE LAS MIRADAS HISTÓRICAS}

Como señala Naredo (2003), al poco de avanzar los estudios económicos dejamos atrás otros enfoques, como la escuela fisiócrata del siglo XVIII en Europa, que partían de considerar actividades primarias (pesca, agricultura, incluso minería) como base y límite de la producción económica. El mundo clásico liberal (Smith 1999) nos situaría precios, mercados y manos invisibles como la totalidad explicativa del universo económico. Aunque en Marx existirá una visión crítica de nuestro metabolismo y una equiparación entre la explotación entre seres humanos con la que la humanidad realiza sobre la naturaleza, el trabajo en sí aparecerá como fuente de la economía (ver Sacristán 1987). Por supuesto, las economías de alta socialidad de los países colonizados poco iban a aportar al entendimiento de cómo sostenemos la vida (Núñez del Prado 2009).

De igual manera, ni el capitalismo ni su crítica económica más extendida se han caracterizado en los últimos siglos por considerar la evolución de los sistemas productivos, distributivos o financieros como impensables sin considerar todo el entramado de economías de cuidados que hubo que comenzar a disciplinar (enclaustrar en el hogar, esencializar la visión de las mujeres y de la naturaleza, nuevo "contrato sexual") ya en el siglo XVI en esta misma Europa (Federicci 2004, Puleo 2011). Décadas después, el reduccionismo eurocéntrico cristalizará en debates como los que enfrentarían el ala precursora del neoliberalismo (Hayek) a las corrientes abiertas a la intervención estatal (Keynes) (ver referencias en Etxezarreta 2015). Al otro lado de la guerra fría, el colonialismo ruso resolvía en forma de planificación centralizada sus propuestas de socialismo para el resto del orbe. Poco margen quedaba para formas de socialismo desde abajo, como proclabama el indigenismo marxista del peruano Mariátegui o el principio de Ujammaa impulsado por Neyrere como ancla de un socialismo de raíces comunitarias África. Menos aún para una crítica colonial de las economías del "hombre blanco", que serían visibles a partir de trabajos como el de Shiva y Mies (1998).

Los 70 y los 80 serán tiempos de bifurcación, que diría el recientemente fallecido Immanuel Wallerstein (1997). Los movimientos sociales protagonizados por estudiantes, ecologistas, pacifistas, feministas o adalides 
de una autonomía social u obrera frente a los grandes dictados políticos y económicos tendrían su correlato en la crítica académica en pos de otras economías. Irán surgiendo enfoques críticos, en ocasiones invirtiendo radicalmente la idea de economía como emanada de un valor creado por trabajos remunerados o mercados monetarios. Surgen planteamientos que deconstruyen la dualización del mundo económico y proponen su superación a través de nuevas miradas. En la economía convencional (capitalista) existe siempre un Norte y un Sur, un sistema monetario que quiere crecer exponencialmente y una realidad planetaria que nos limita, algunos centros y muchas periferias, un valor dado a la circulación por mercados remunerados y una invisibilización de cuidados cotidianos. Nacen las primeras visiones alternativas al "desarrollo" con acento en el rechazo a la dependencia (trabajos de CEPAL o Sami Nair; ver Rist 2002), la apuesta por lecturas más contextualizadas de los satisfactores que nos aproximan a las necesidades (en versión de los trabajos de M. Neef, Elizalde; ver Calle y Gallar 2011), todo ello en medio de un auge de agendas anti-desarrollistas (Cumbre Oslo, Manifiestos por la sostenibilidad que desembocaría en Río 1992). La creciente consciencia de los límites ambientales y las injusticias sociales va abriendo paso a nuevas y grandes enfoques económicos que están detrás de esas otras economías. Es el caso del ecosocialismo en el campo marxista más heterodoxo (ver Riechmann 2012); los primeros pasos para una economía que se considerara inserta en un mundo limitado por flujos de materias y energías (Georgescu-Roegen; ver Naredo 2003); la economía institucional que nos hablaba de la importancia de los comunales para la sostenibilidad del planeta (E. Ostrom 2010); la geografía crítica que sitúa en formas coloniales (ver Porto-Gonçalves 2017) y de depredación (Harvey 2019) las formas de apropiación bajo economías "globalizadas"; $y$, avanzado el siglo XX, las bases para enfoques económicos feministas donde de la desigualdad de género se pase a visualizar como central el trabajo reproductivo en los hogares (ver Carrasco 2001).

\section{ECONOMÍAS-OTRAS: ATERRIZANDO ALTERNATIVAS HACIA LOS NUEVOS COMUNES}

En conjunto, toda la crítica anterior va conformando los contornos de cómo entender las Economías-Otras, más caracterizables por sus prácticas que por la intención de establecer un corpus rígido que las encierre en lugar de expandirlas. Entre los cuatro puntos más relevantes que nos explican el común de estas Economías-otras están, a nuestro entender:

- más allá del Estado, de los mercados monetarios y las grandes empresas, al otro lado de cercamientos que sitúan en el centro actualmente la economía capitalista 
- más cercanas a las bases ecológicas, hogareñas y de mediación necesaria para la reproducción cuerpos, hábitats y lazos sociales

- más ancladas en territorios concretos, más (re)localizadas y experimentadas a través de miradas e incluso comunidades que, en buena parte de los casos, serán "de destino" (recomposición de lazos sociales) antes que "esenciales" (tradicionales o forjadas mediante un relato histórico común)

- más conscientes de aunar sostenibilidad, justicia social y de construir una democracia desde abajo que abarque lo cultural y lo económico

Son economías del presente porque disputan y desafían referentes hoy. Por ejemplo, las sociedades en países industrializados precisan de una dedicación más que importante a temas reproductivos y comunitarios. Según la Encuesta Nacional de Condiciones de Trabajo 2015 que se realizó en España, un hombre en una pareja con hijos dedicará cerca de 21 horas semanales a actividades en el hogar, no remuneradas, tiempo que ascenderá a 37,5 horas por semana para mujeres. $Y$ en el caso de economías productivas, aquella que formaría parte del cooperativismo formal en la Unión Europea, donde no todo es Economía Social y Solidaria, viene a representar 14,5 millones de trabajadores/as. En el caso de Brasil, con datos de 2006, formalmente suponía un empleo para 2 millones de personas.

Son economías del mañana porque albergan condiciones de factibilidad (pensando en términos inclusivos y no de modelos sociales piramidales) para garantizar una transición que nos aleje de propuestas de cercamiento más intenso por parte de unas élites. Con el actual modelo de consumo estamos depredando los recursos de un planeta y medio, al margen de hacer uso de materiales y energías cuyo pico de producción ya hemos pasado y estamos adentrándonos en zona de escasez y difícil acceso. Algo manifiestamente insostenible para cualquier sistema económico y que en el pasado representó el ecocidio de alguna que otra civilización (Broswimmer 2009). La agricultura industrial es en la actualidad un sistema que se dedica a quemar petróleo para (sub)alimentar a la humanidad: es responsable entre producción y distribución de más del $50 \%$ de gases invernadero que vertemos a nuestros cielos, a la vez que genera hambrunas y dietas hipercalóricas para millones de personas.

Son economías-otras porque su condición es de caminar hacia propuestas económicas alternativas y emancipadoras, poniendo freno a la extralimitación ecológica; a la vez que la diversidad se percibe como muy enriquecedora, al aplicarse a diferentes contextos y manejar temas candentes en torno al poder como la interseccionalidad derivada de desigualdades yuxtapuestas. Son laboratorios pues atraen dinámicas sociales cuando la economía insiste en hacer naufragar la vida humana. 
Frente a la depresión y el desgaste de lazos nos plantea otras formas de bienestar y de construir comunidades (de destino o intencionales en muchos casos), como argumenta el economista T. Jackson (2017) en su análisis centrado en países más ricos. Un estudio en Australia pone de manifiesto que $23 \%$ de encuestados habían tomado parte en los últimos años en iniciativas que tienen que ver con relocalización de las economías y simplificación/eliminación de sus formas de consumo. Ratios que se mejoran para estudios similares en Estados Unidos y Europa. Desde aquí la idea es afrontar de manera local problemas que se manifiestan globalmente y como consecuencia de la globalización. Iniciativas que "enfatizan las ventajas colectivas de una vida menos imbuida por el materialismo y menos intensiva en energía" (Jackson 2017: 129). Energía que no estará disponible, materialismo consumista que no da la felicidad. Además, consumir menos de forma voluntaria es un indicador para la mejora de un "bienestar subjetivo", en oposición a economías que se esfuerzan en crecer y no dejan de formar "idiotas" e infelices.

\section{LAS ECONOMÍAS-OTRAS EN ESTE MONOGRÁFICO.}

Las economías-otras componen un árbol genealógico diverso, de miradas y prácticas, pero todas ellas disputan, de manera esencial, la cuestión del poder y de la (in)sustentabilidad derivadas al desafiar la economía capitalista y otros cercamientos que nos imposibilitan satisfacer nuestras necesidades humanas (ver Calle, Piñeiro, Suriñach 2017). Así, los referentes de la Economía Social y Solidaria (Coraggio 2009) nos aportan una fuerte actualización del cooperativismo en clave de colectivización económica y redistribución, en cuanto a su crítica del poder; a la par que avanza en ligar la sostenibilidad a un cierre de circuitos materiales, energéticos y políticos en un contexto dado. Las Economías del cuidado (Carrasco, Borderías y Torns 2011) insisten en cómo todo modo de integración económico ha de rodearnos de un haz de atenciones materiales y afectivas, como se ha hecho históricamente, particularmente mujeres en situaciones de desigualdad y opresión. Visibilizan la red de cuidados a la par que denuncian la dicotomía entre trabajo productivo-remunerado y trabajo reproductivo-invisibilizado base de la negación patriarcal de las mujeres y de trabajos preferentemente realizados por ellas.

Economías ecológicas y de base campesina, que inspiran hoy la agroecología o las propuestas de decrecimiento con justicia, nos hacen comprender el carácter co-evolutivo del mundo (sociedades empotradas en ciclos vitales que gobierna un planeta) y, por tanto, la necesidad de imitar o acompañar procesos que eviten la ruptura de ciclos vitales esenciales para la vida. De ahí muchas iniciativas entienden el respeto que se ha de tener por la diversidad cultivada en nuestros entornos (frente a 
la ganadería y la agricultura intensivas) o la necesidad de cerrar circuitos materiales y energéticos en un territorio dado (compostaje, desarrollo de energía sostenible, ideas de "kilómetro cero"). No hay planeta B, por lo que se hacen urgentes aplicar fuertes dosis de biomímesis o imitación/respeto de los ciclos naturales (Riechmann 2008) y de recomposición de nuestros intercambios desde abajo para promover una Democracia en la Tierra (Shiva 2016) para recuperar una conciencia de especie (Toledo 2010) y una posibilidad de que el capital no arrase nuestra (humana) vida (Pérez-Orozco 2014). Todo ello conforma hoy un gran abanico de formas de aproximarse a las economías con acento en la sustentabilidad social y ambiental, en modos de integración donde la atención a cuestiones de bienestar, lazos, hogar, planeta y democracia están en primera línea. Creemos que todas estas propuestas pueden leerse, de forma práctica y no desde una filosofía política, como alimentadores del auge de Nuevos comunes ${ }^{8}$. Esta aproximación aquí expuesta a la economía y estas economías-otras, pretende ser reflejada en el desarrollo de este monográfico. Un enfoque sistémico pasa por visibilizar las múltiples dimensiones del sistema económico que buscamos transformar.

Se hace difícil en una publicación, al igual que en el día a día de las alternativa, incorporar el carácter interseccional necesario para avanzar en las transiciones pero creemos que el primer paso está en visibilizar distintas miradas y construcciones y poder compartir los aprendizajes que día a día se extraen de cada una de ellas. Este documento pretende ser un modesto aporte a todas las nuevas construcciones que se dan en el día a día, en la calle, en los hogares, en los barrios y en las distintas trincheras desde las que cada persona trabaja en lo cotidiano.

Abordamos en este monográfico la necesidad de introducir nuevas miradas sobre la economía: alternativas a la idea del desarrollo, la necesidad de una perspectiva feminista, la crítica de las propias alternativas y los riesgos de convencionalización, junto con un análisis del potencial de los Nuevos comunes. Las experiencias y los retos concretos nos hablarán de esas Economías-otras a través de los campos de la agroecología, alteranativas de consumo, comunales y la política del procomún en los campos de la cultura, la energía y la economía social y solidaria.

La guía para la transición, tal y como exponemos, han de ser las necesidades y el colocar en el centro el cuidado de las personas y el planeta. Algo sin duda difícil e incluso arriesgado en estos tiempos donde la inestabilidad y la precariedad lleva a muchas a tener que pedalear

8 Podríamos hablar también de Comunes globales, en tanto que tienen una vocación de atender el cuidado conjunto de bienes naturales y cooperativos, en medio de un mar de problemas planetarios (Ver Calle 2016) 
(literalmente) bajo la tormenta. La capacidad de adaptación y de resiliencia es sin duda algo a desarrollar, pero también la resistencia a modelos depredadores cuyo desarrollo pasa por la anestesia social con el objetivo de normalizar e incluso naturalizar la desigualdad y la "no vida".

Todo esto pasa por el mantenimiento o la re-construcción en su caso de lazos sociales y la definición de lo económico y lo comunitario en el Siglo XXI. En momentos donde se confunden interacciones virtuales con relaciones y donde la inmediatez junto a la individualidad inundan nuestras pantallas. No son los mejores tiempos para procesos que piensen en clave de transición y proceso, pero la urgencia promete ser un catalizador importante.

\section{BIBLIOGRAFÍA}

Aguilera Klink, F. (2013): "Sobre la deshumanización de la economía y de los economistas". Mediterráneo Económico, 23, 5-29

Aguilera Klink, F. (2016): "La corrupción como traición a la comunidad", Papeles de relaciones ecosociales y cambio global, n. 135

Broswimmer, F. (2009): Ecocidio, Laetoli, Navarra.

Calle Collado, Á. (2013). La transición inaplazable: salir de la crisis desde los nuevos sujetos políticos, Icaria, Barcelona.

Calle, A. (2015): "La relevancia económica y política del enfoque de los bienes comunes" Kultur: revista interdisciplinària sobre la cultura de la ciutat, Vol. 2, N. 3, (Ejemplar dedicado a: Emancipació, autogestió i canvi), 55-76, [disponible en https://dialnet.unirioja.es/servlet/ articulo?codigo $=5128004]$

Calle (2018): "La ultraderecha: el voto productivista contra el mundo", El Diario, 13/12/2018, [https://www.eldiario.es/ultima-llamada/ ultraderecha-voto-productivista-mundo_6_843125696.html]

Calle, A. y Gallar, D. (2011): "Estamos en medio: necesidades básicas, democracia, poder y cooperación" en Calle Collado, Ángel, Democracia Radical: entre vínculos y utopias, Icaria, Barcelona.

Calle, A. Piñeiro, C. y Suriñach R. (2017): Comunes y economías para la sustentabilidad de la vida, en Comunaria coord.

Carpintero, Ó. (2004): El metabolismo económico de España: Flujos de energía, materiales y huella ecológica (1955-2000), Fundación César Manrique, Lanzarote.

Carpintero, Ó. (dir.) (2015): El metabolismo económico regional español, FUHEM Ecosocial, Madrid.

Carrasco, C. (2006): "La economía feminista: Una apuesta por otra", Estudios sobre género y economía, 15, 29.

Carrasco, C., Borderías, C., y Torns, T. (2011): El trabajo de cuidados, Catarata, Madrid. 
Carrasco, C., y Tello, E. (2013): "Apuntes para una vida sostenible", Tejiendo alianzas para una vida sostenible. Consumo crítico, feminismo y soberanía alimentaria, 11-44.

Castells, M (ed.) (2008): La sociedad red: una visión global, Alianza Editorial, Madrid.

Castoriadis, C. (2005): Escritos políticos, Los Libros de la Catarata, textos editados por Xavier Pedrol, Madrid.

Coraggio, J. L, org. (2009): ¿Qué es lo económico? Materiales para un debate necesario contra el fatalismo, CICCUS, Buenos Aires.

Damasio, A. (2018): El extraño orden de las cosas, Ediciones Destino, Madrid.

Ezquerra, S. (2011): "Crisis de los cuidados y crisis sistémica: la reproducción como pilar de la economía llamada real", Investigaciones Feministas, vol. 2, p. 175-194

Etxezarreta, M. (2015): ¿Para qué sirve realmente la economía?, Ediciones Paidós, Barcelona.

Federici, S. (2004): El Calibán y la bruja: Mujeres, cuerpo y acumulación originaria, Traficantes de Sueños, Madrid.

Fernández Durán, R. y González Reyes, L. (2014): En la espiral de la energía (Dos tomos: Historia de la humanidad desde el papel de la energía (pero no solo) y Colapso del capitalismo global y civilizatorio), Libros en Acción, Madrid.

Gálvez Muñoz, L. y Torres López, J. (2010): Desiguales. Mujeres y hombres en la crisis financiera, Icaria, Barcelona.

Gibson-Graham, J. K. (2011): Una política poscapitalista, Siglo del hombre editores, Bogotá.

González Reyes, L. (2019): "Sobre el papel del Estado en el cambio civilizatorio en curso", Revista Contexto (19-01-201), [disponible en https://ctxt.es/es/20190130/Politica/24185/en-la-espiral-de-la-energiaestados--combustibles-fosiles-autogestion-luis-gonzalez-reyes.htm]

Harvey, D. (2019): La Lógica Geográfica Del Capitalismo, Icaria, Barcelona.

Herrero, Y. y González Reyes, L. (2011): "Decrecimiento justo o barbarie", Revista Pueblos, n. 49.

Herrero, Y., Cembranos, F., y Pascual, M. (Eds.). (2015): Cambiar las gafas para mirar el mundo: una nueva cultura de la sostenibilidad, Libros en Acción, Madrid.

Husson, M. (2013): El capitalismo en diez lecciones, La Oveja Roja, Madrid Jackson, T. (2017): Prosperity without Growth. Foundations for the economy of tomorrow, Routledge, 2017, segunda edición, Londres.

Kallis, G., y Norgaard, R. B. (2010): "Coevolutionary ecological economics", Ecological Economics, 69(4), 690-699. https://doi.org/10.1016/j. ecolecon.2009.09.017 
Laval, C. y Dardot, P. (2016): La nueva razón del mundo: Ensayo sobre la sociedad neoliberal, Editorial Gedisa, Barcelona.

Lenore, V. (2018): Indies, hipsters y gafapastas: crónica de una dominación cultural, Capitán Swing, Madrid.

Moruno, J. (2015): La fábrica del emprendedor. Trabajo y política en la empresa-mundo, Akal, Madrid

Mounk, Y. (2018): El pueblo contra la democracia. Por qué nuestra libertad está en peligro y cómo salvarla, Paidós, Madrid.

Naredo, J. (2003) [1996]: La economía en evolución. Historia y perspectivas de las categorías básicas del pensamiento económico, Siglo XXI, reed. Actualizada, México-Madrid.

Núñez del Prado, J. (2009): Economías indígenas: estados del arte desde Bolivia y la economía política. CIDES-UMSA, La Paz.

Ostrom, E. (2010): El gobierno de los comunes. La evolución de las instituciones de acción colectiva, Ed FCE,.México.

Pérez Orozco, A. (2006): Perspectivas feministas en torno a la economía: el caso de los cuidados, Consejo Económico y Social, Madrid.

Pérez Orozco, A. (2014): Subversión feminista de la economía. Aportes para un debate sobre el conflicto capital-vida, Traficantes de Sueños, Madrid.

Piñeiro, C.; Suriñach, R. y Casadevante, J.L. (2017): "El consumo colaborativo en el contexto de la transformación social: limitaciones y potencialidades de estas prácticas" RES (aceptado).

Polanyi, K. [1977] (2009): El sustento del hombre, Capitán Swing, Madrid. http://opcions.org/es/nos-gusta/las-economias-transformadoras/

Porro, A. (2017): "¿Qué son las economías transformadoras?", Revista Opcions, 29.05.2017, []

Porto-Gonçalves W. (2017): "Lucha por la tierra", en Alimonda, H., Toro, C. \& Martín, F. (comp.), Ecología política latinoamericana. Pensamiento crítico, diferencia latinoamericana y rearticulación epistémica, CLACSO, Buenos Aires.

Prats, F., Herrero, Y. y Torrego, A. (2016): La gran encrucijada, Libros en Acción y Editorial Icaria, Madrid/Barcelona

Prats, F. (2019): "Emergencia climática y proyecto de país", eldiario.es 10/09/2019, [disponible en https://www.eldiario.es/ultima-llamada/ Emergencia-climatica-proyecto-pais_6_937966195.html]

Prieto, P. (2019): "Energías renovables: Potencia instalada vs. factor de carga, crecimiento, demanda, porcentajes, producción...", Revista 15-15-15, 2019-07-14, [disponible en https://www.15-15-15.org/ webzine/2019/07/14/energias-renovables-potencia-instalada-vs-factorde-carga-crecimiento-demanda-porcentajes-produccion/]

Puleo, A. H. (2013). Ecofeminismo para otro mundo posible, Ediciones Cátedra, Madrid. 
Riechmann, J. (1998): Necesitar, desear, vivir: sobre necesidades, desarrollo humano, crecimiento económico y sustentabilidad, Catarata, Madrid.

Riechmann, J. (2003): Cuidar la T(t)ierra, Icaria, Barcelona.

Riechmann, J. (2008): ¿En qué estamos fallando?: cambio social para ecologizar el mundo. Icaria Editorial, Barcelona.

Riechmann, J. (2012): El socialismo puede llegar sólo en bicicleta, Madrid, Libros La Catarata.

Rist, G. (2002): El desarrollo: historia de una creencia occidental, Los Libros de la Catarata, Madrid.

Rowlands, J. (1998): "Empoderamiento y mujeres rurales en Honduras: un modelo para el desarrollo", en Magdalena León (comp.), Poder y empoderamiento de las mujeres, Tercer Mundo Editores, Bogotá Colombia.

Sacristán, M. (1987): Pacifismo, ecología y política alternativa, Barcelona, Icaria Santiago Muiño, E. (2019): "Cambio climático y transición ecológica. ¿Anticipación de emergencia o Green New Deal?", Revista El Ecologista, n. 99. [disponible en https://www.ecologistasenaccion.org/118569/ cambio-climatico-y-transicion-ecologica-anticipacion-de-emergencia-ogreen-new-deal/]

Santiago Muiño, E. y Tejero Franco, Héctor (2019): ¿Qué hacer en caso de incendio? Manifiesto por el Green New Deal, Capitán Swing, Madrid.

Sassen, S. (2013): Territorio, autoridad y derechos: de los ensamblajes medievales a los ensamblajes globales, Katz editores, Buenos Aires.

Shiva, V. (2006): Manifiesto para una democracia de la tierra: justicia, sostenibilidad y paz, Ediciones Paidós, Barcelona.

Smith, A. (1999): La riqueza de las naciones, Alianza Editorial, Madrid.

Thompson, E. P. (2019): Costumbres en común. Estudios sobre la cultura popular, Capitán Swing.

Toledo, V. (2010): "Las claves ocultas de la sostenibilidad transformación cultural, conciencia de especie y poder social ", en La situación del mundo: informe anual del Worldwatch Institute sobre progreso hacia una sociedad sostenible, FUHEM/WWI, Madrid.

Tousaint, E. (2018): El Sistema Deuda. Historia de las deudas soberanas y de su repudio, Icaria, Barcelona

Turiel, A. (2018): "¿Trabaja usted en el sector del automóvil? Pues sepa que le están engañando", noviembre de 2018 en blog http://crashoil. blogspot.com/2018/11/

V.AA (2019): Decrecimiento frente a Green New Deal, Traficantes de Sueños, Madrid.

Wallerstein, I. (1997): El futuro de la civilización capitalista, Icaria, Barcelona. 